\title{
Application of Simulation Technology in Military Education
}

\author{
Yutong Chen* \\ Officers College of People's Armed Police, Guangzhou 510000, China \\ *Corresponding author: Yutong Chen, magnum163@163.com
}

\begin{abstract}
Based on the teaching characteristics in military academies, simulation technology has been applied in their teaching methods. The issues faced in the application of virtual simulation technology to relevant professional teaching in armed police academies are analyzed in this article. Secondly, in view of the difficulties encountered in the organization and implementation of practical teaching as well as in the development of the current teaching, this article explores the impact of simulation technology in its application in teaching methods, training practices, and teaching channels.
\end{abstract}

Keywords: Simulation technology; Military education; College education

Publication date: September 2021; Online publication: September 30, 2021

\section{Introduction}

In recent years, with the rapid development of computer technology and information technology, virtual simulation technology has gradually become popular in various industries and has become an important part of modern society. The educational goal of military academies is to train qualified military personnel for the army. The implementation of tasks in armed police forces such as counter-terrorism, emergency handling, and on-duty, puts forward new requirements for these academies to train up a new kind of military personnel in line with the new era. It can be seen from this that the cultivation of outstanding military personnel who can fight and win wars has become an important topic of national defense in this era.

\section{Problems existing in the teaching of military academies at this stage}

\subsection{Teaching ideas require improvement}

Although military education has developed, it is unable to keep up with the pace of the information age. To a certain extent, it still remains at the previous "flooding" and "crawling" teaching methods, failing to adapt to the rapid development in the new era and the requirements of the society. At present, most of the inservice teaching staffs in military academies follow the traditional teaching method; that is, using teaching plans and presentations to carry out teaching in multimedia classrooms. Only a few courses have specialized training rooms or simulation laboratories with specific conditions; even so, these courses are rarely conducted in these classrooms. These classrooms are not fully utilized, and the vacancy rate is high, resulting in a waste of teaching resources in military academies.

\subsection{Difficulties in developing practical teaching}

The military education of armed police forces is centered on practical training. The requirements for practical training are increasing day by day. However, due to the lack of teaching venues, insufficient teaching funds, and other factors, the practical training of certain courses cannot be carried out well, 
affecting the teaching quality of the courses. Therefore, the teaching conditions need to be improved. In addition, the practical training in certain courses may place the teaching staffs and students in dangerous situations, posing a threat to their lives. Taking the firepower unit and special forces unit of the armed police force as an example, when conducting Howitzer training or assessment, there are high requirements for site setup, security, and position management. When a non-explosive bomb goes off during shooting, it is more difficult to search for and eliminate it. Generally, the teaching staffs would demonstrate the process of disassembling non-explosive bombs while the students watch in the vicinity. The disassembling of nonexplosive bombs is carried out under the supervision of the teaching staffs. If the teaching staffs or students do not have sufficient safety awareness during the operation or the teaching activity is not carried out in accordance with the safety regulations, safety hazards may occur. Therefore, carrying out teaching tasks under potentially dangerous situations have a relatively high safety risk factor. Ensuring the personal safety of the teaching staffs and students in the teaching process while maintaining the quality of teaching is also an issue that needs to be considered.

\section{Impact of simulation technology on the military education of the armed police force}

\subsection{Improve the teaching methods and contents}

The widespread use of information technology has profound impact on all walks of life in the society. For military education, it has a profound impact on its teaching methods. Among them, the integration of virtual simulation technology into military education can improve the teaching efficiency in military academies of the armed police force, enabling the achievement of better teaching effects and also improving the degree of informatization in the teaching process. Using this kind of teaching method does not only promote students' learning enthusiasm and create a livelier classroom atmosphere, but also assist in combining teaching work with training practice. For classroom teachings that are carried out in the traditional way, multimedia courseware is often used, and methods such as lectures and demonstrations are used to enable students to understand theoretical knowledge before conducting practical courses outdoors. The latter requires more consideration in terms of the weather, venue, and equipment, otherwise the practical training and teaching work cannot be carried out smoothly, thus affecting the quality of teaching. In addition, the spread of epidemic diseases would also affect the development of normal practical training and teaching tasks. Due to the new crown pneumonia epidemic in recent years, the government has banned gathering activities in public places. As a result, traditional classroom teaching and outdoor training courses cannot be carried out normally; instead, teaching can only be carried out through online remote teaching. In view of that, teaching staffs have started to use multimedia teaching, virtual simulation technology, and network technology to conduct training, assessment, and evaluation of their students, thus reducing the impact of the epidemic on classroom teaching and ensuring its smooth implementation.

\subsection{Increase the opportunities for training practice}

In many colleges and universities that are affiliated to the armed police force, more emphasis should be on the teaching of operational practice rather than the teaching of theoretical courses. Even so, it is hardly possible to prepare the training equipment required for the teaching in military academies in time due to various factors. As a result, the students have insufficient practice or even lose out on practice opportunities. In view of that, it is difficult to achieve an ideal teaching effect. To make matters worse, when these students or soldiers return to their original units after completing their training tasks, it is difficult for them to gain hold of time and the opportunity to practice with these weapons or equipment. When these weapons are required for use, the officers and soldiers have to familiarize with them again, thus consuming extra time and energy. In view of the above problems, virtual simulation technology can be used to restore the teaching 
scene and simulate training on computers or mobile devices at military academies so that students would not only have the opportunity to train in classrooms, but also familiarize with these weapons and equipment during their spare time, which can be done anytime and anywhere. Simulation training improves learning efficiency and cultivates good learning habits. It can be seen that the integration of virtual simulation technology into military education is beneficial to overcome the difficulties encountered in organizing and implementing practical teaching as well as the high requirements for practice sites. In addition, it improves the efficiency of military academies in carrying out practical training and teaching work, cultivates highquality military personnel under the standards of actual combat in the new era in order to lay a solid foundation for the country, and enables trainees to master operational skills after completing training to successfully serve in the army.

\section{Conclusion}

The introduction of virtual technology into military education has become an important trend in the informatization of national defense education for the future. It can effectively solve many problems existing in the education at military academies. With the development of information technology and military education, simulation technology will continue to promote the reform of military academies and practical training as well as provide new ideas for the modernization of military education.

\section{Disclosure statement}

The author declares that there is no conflict of interest. 